\title{
Specialist prescribing of psychotropic drugs to older persons in Sweden - a register-based study of 188024 older persons
}

Gunilla Martinsson ${ }^{1,2^{*}}$, Ingegerd Fagerberg ${ }^{1,3}$, Lena Wiklund-Gustin ${ }^{2,4}$ and Christina Lindholm ${ }^{5}$

\begin{abstract}
Background: The situation for older persons with mental disorders other than dementia disorders has scarcely been studied. The older population is increasing worldwide and along with this increase the prevalence of mental disorders will also rise. The treatment of older persons with mental disorders entails complex challenges, with drugs constituting the major medical treatment. Knowledge of geriatric psychiatry is essential for providing older persons with appropriate treatment and care. This study aimed to evaluate the prescription of drugs for mental disorders to older persons $(265)$ in Sweden, focused on the medical specialties of the prescribing physicians.

Methods: Data concerning drug treatment for older persons from 2006 to 2008 was gathered from the Swedish Prescribed Drug Register. Mental disorders, defined as affective, psychotic and anxiety disorders (ICD-10 F20-42) were evaluated in order to identify associated drugs. Included was a total of 188024 older individuals, who collectively filled 2013079 prescriptions for the treatment of mental disorders. Descriptive analyses were performed, including frequency distribution and $95 \% \mathrm{Cl}$. The competence of the prescribers was analyzed by subdividing them into five groups: geriatricians, psychiatrists, general practitioners (GPs), other specialists, and physicians without specialist education.
\end{abstract}

Results: GPs represented the main prescribers, whereas geriatricians and psychiatrists rarely prescribed drugs to older persons. Benzodiazepines and tricyclic antidepressants were the most commonly prescribed drugs. Women were prescribed drugs from geriatricians and psychiatrists to a greater extent than men.

Conclusions: This study examined the prescription of psychotropic drugs to older persons. Physicians specialized in older persons' disorders and mental health were rarely the prescribers of these drugs. Contrary to clinical guidelines, benzodiazepines and tricyclic antidepressants were commonly prescribed to older persons, emphasizing the need for continuous examination of pharmaceutical treatment for older persons. The results indicate a future need of more specialists in geriatrics and psychiatry.

Keywords: Aged, Geriatric, Mental disorders, Older persons, Physicians, Prescribing, Psychiatry, Psychotropic drugs, Register-based

\footnotetext{
* Correspondence: gunilla.martinsson@mdh.se

${ }^{1}$ Department of Neurobiology, Care Sciences and Society, Karolinska

Institutet, Stockholm, Sweden

${ }^{2}$ School of Health, Care and Social Welfare, Mälardalen University, Västerås,

Sweden

Full list of author information is available at the end of the article
}

\section{Biomed Central}

(c) 2012 Martinsson et al.; licensee BioMed Central Ltd. This is an Open Access article distributed under the terms of the Creative Commons Attribution License (http://creativecommons.org/licenses/by/2.0), which permits unrestricted use, distribution, and reproduction in any medium, provided the original work is properly cited. 


\section{Background}

The world is facing a demographical shift in which the older population will increase. It is thus fair to assume that the prevalence of disorders that are common among older persons will also increase. Studies have shown that mental disorders are prevalent among the old [1-3], even when dementia disorders are excluded $[4,5]$. The treatment of mental disorders (i.e. affective, psychotic and anxiety disorders) in older persons is a complex task and can be affected by a variety of factors, including pharmacokinetic and pharmacodynamic changes related to age, influences of concurrent disorders and possible adverse drug reactions. Although the risk of adverse drug reactions increases with age, drug treatment is common among older persons, both nationally [6] and internationally [7]. As older persons are often treated for several conditions besides mental disorders, the possibility for unwanted drug interactions is increased in this age group. Indeed, several studies have reported that older persons are subjected to polypharmacy and inappropriate drug use [8-10], and that many hospitalizations occur due to drug related problems [11].

The treatment of mental disorders often involves several different physicians, raising questions about who ultimately carries the responsibility for the adequacy and quality of the combined pharmaceutical regime. In addition, the time allocated to mental health issues during consultations with physicians is generally low [12] and the combination of several prescribers commonly entails more drugs and lower overall quality of care [13]. At present, very little time (at most two weeks) is allocated to the field of geriatrics during the training to become a licensed physician in Sweden [14]. Specialists in geriatrics and psychiatry represent approximately $2 \%$ and $6 \%$, respectively, of the licensed physicians in Sweden, while physicians with specialist education in general medicine (general practitioners, GPs) represent 18\% [15]. Hence, there is an obvious lack of physicians with specialized skills in treating older persons with mental disorders.

GPs providing care for older persons have reported feeling insecure when required to surpass their own competence, as well as a lack of communication with other physicians and specialists [16]; these factors can negatively impact the treatment and care given to older persons with mental disorders. Studies have demonstrated that treatment by geriatric teams reduces mortality $[17,18]$ and increases the possibility for older persons to remain at home $[19,20]$. Although the particular knowledge that geriatricians acquire is vital in providing older persons with adequate treatment and care, health care personnel tend to prefer interdisciplinary teams comprising different medical specialties when treating and caring for older persons with or without mental disorders [21,22]. Psychiatrists in particular contribute important knowledge on mental health and, as they generally hold more positive professional attitudes towards people with mental disorders such as schizophrenia [23], they would preferably be included in such a team.

The current situation for older persons with mental disorders has scarcely been studied and questions have been raised as to whether or not older persons with extensive needs receive adequate care and treatment. In order to facilitate the improvement of treatment and to reduce possible adverse drug reactions among older persons with mental disorders, it is important to evaluate the amounts and types of drugs older persons are being prescribed and which medical specialties their prescribers hold.

\section{Aim}

This study aimed to evaluate the prescription of drugs for mental disorders to older persons ( $\geq 65$ years) in Sweden during the three-year period from 2006 to 2008, focusing on the medical specialties among the prescribing physicians and the amount of drugs prescribed to older men and women.

\section{Methods}

\section{Study population}

All persons in Sweden aged 65 years and older were included in this analysis if they had received one or more registered prescriptions for drugs for mental disorders included in the International Classification of Diseases, version 10 (ICD-10) F20-F42 [24] during 2006, 2007 or 2008. A total of 188024 individuals, who together received 2013079 dispensed drugs for mental disorders during the years 2006, 2007 and 2008, were included in the study.

\section{Data measurement}

The Swedish Prescribed Drug Register (SPDR) from the Swedish National Board of Health and Welfare was the source for the data included in the analysis. All personal information was replaced with serial numbers. The variables included were age (65 years and older), sex, ATC codes (level 5; chemical substance), prescribing and dispensing dates, as well as the specialist codes for the prescribers.

\section{Data collection and analysis}

The SPDR was used to explore the prescription of drugs for mental disorders to older persons. Complete information about the drugs dispensed at national pharmacies is included in the register. As social security numbers were introduced to the register in 2005 , the analyses were carried out using data from 2006 to 2008 . Older persons receiving prescriptions for drugs indicated or recommended in the Swedish Medicines Information portal [25-28] for use in psychotic (F20-29, ICD-10), affective (F30-39, ICD10) and anxiety (F41-42, ICD-10) disorders, Chapter V, 
ICD-10 [24] were included in the analysis. The Anatomical Therapeutic Chemical Classification (ATC) codes, level 5, were subsequently applied (see Table 1). Drugs intended for use in dementia disorders (ICD-10: F00-03; ATC: N06DA02-04, N06DX01) or recommended as firsthand choice in dementia disorders (ATC: N05AA-AX, N05CF-CM, N06AB, N06DA-DX) have been excluded to avoid analyzing persons with diffuse symptoms that could be classified as either mental disorders or dementia disorders. All prescriptions filled and dispensed during the three-year period were included in the analysis.

The Swedish system for attaining a specialist degree as a physician includes at least five years of full-time specialization education following undergraduate studies and involves working under supervision and attending complementary education. During the years 2006, 2007

Table 1 Evaluated disorders from International Classification of Diseases version 10 (ICD-10), Chapter V Mental and behavioral disorders: F20-29 (schizophrenia, schizotypal and delusional disorders), F30-39 (affective disorders), F41 (other anxiety disorders) and F42 (obsessive-compulsive disorders); the applied ATC codes level 5 and the corresponding chemical substances included in the study

\begin{tabular}{|c|c|c|c|c|c|}
\hline ATC level 5 & Chemical substance & F20-29 & F30-39 & F41 & F42 \\
\hline N03AE01 & Clonazepam & & & & $x$ \\
\hline N03AF01 & Carbamazepin & & $x$ & & \\
\hline N03AG01 & Valproic acid & & $x$ & & \\
\hline N03AX09 & Lamotrigine & & $x$ & & \\
\hline N03AX16 & Pregabalin & & & $x$ & \\
\hline N04BC05 & Pramipexole & & $x$ & & \\
\hline N05BA01 & Diazepam & $x$ & $x$ & $x$ & \\
\hline N05BA04 & Oxazepam & $x$ & $x$ & $x$ & \\
\hline N05BA06 & Lorazepam & $x$ & $x$ & $x$ & \\
\hline N05BA12 & Alprazolam & $x$ & $x$ & $x$ & \\
\hline N05BE01 & Buspirone & & $x$ & $x$ & \\
\hline N06AA04 & Clomipramine & $x$ & & $x$ & $x$ \\
\hline N06AA06 & Trimipramine & $x$ & $x$ & & \\
\hline N06AA09 & Amitriptyline & $x$ & $x$ & & \\
\hline N06AA10 & Nortriptyline & $x$ & $x$ & & \\
\hline N06AA21 & Maprotiline & $x$ & $x$ & & \\
\hline N06AG02 & Moclobemide & & $x$ & & \\
\hline N06AX02 & Tryptophan & & $x$ & & \\
\hline N06AX03 & Mianserin & & $x$ & & \\
\hline N06AX11 & Mirtazapine & & $x$ & & \\
\hline N06AX12 & Bupropion & & $x$ & & \\
\hline N06AX16 & Venlafaxine & & $x$ & & \\
\hline N06AX18 & Reboxetin & & $x$ & $x$ & \\
\hline N06AX21 & Duloxetine & & $x$ & & \\
\hline N06BA07 & Modafinil & & $x$ & & \\
\hline
\end{tabular}

and 2008 there were a total of 62 different specialties possible for physicians, and a given physician may hold several different specialties. In the data analyses, the specialist categories were divided into four groups: general practitioners (GPs), geriatricians, psychiatrists (including specialist education in forensic psychiatry as well as children and young peoples' psychiatry) and "other specialists" comprising all other specialists. Licensed physicians with no specialist education were analyzed separately. Descriptive univariate analyses with frequency distribution and 95\% CI were carried out using IBM SPSS Statistics 19.0 for Windows (SPSS Inc. an IBM company, 1989-2010).

The regional ethics board in Uppsala, Sweden critically and ethically revised and approved this study to be compliant with the Helsinki Declaration [29] (Reference number 2008/345/2).

\section{Results}

On average, $7 \%$ of the older population was prescribed drugs for mental disorders during the years 2006, 2007 and 2008 (see Table 2), with more than one-half million prescriptions dispensed to the older population at national pharmacies each year. Women constituted twothirds and men one-third of the older population receiving these drugs.

Drugs corresponding to 25 different ATC codes, level 5 , were dispensed to older persons $(\geq 65)$ in Sweden from 2006 to 2008, all of which were included in the analysis (see Table 3). Each ATC code corresponds to one specific chemical substance and may have several brand names. The most commonly prescribed and dispensed chemical substances during each of the three years were the benzodiazepines oxazepam and diazepam (anxiolytics), as well as the non-selective monoamine reuptake inhibitor amitriptyline (antidepressant). The amount and frequency of prescriptions for many of these chemical substances changed over the course of the three years: a decrease was seen in prescriptions for $48 \%$ of the substances and an increase for $24 \%$.

On average, during the period from 2006 to 2008, two-thirds (65\%) of the prescribing physicians were GPs (see Figure 1), whereas approximately $4 \%$ were geriatricians and $3 \%$ psychiatrists. Approximately $14 \%$ of the prescribers were physicians with specialist education other than the aforementioned, the majority of whom were specialists in internal medicine, cardiology or neurology. Physicians without any specialist education corresponded to $14 \%$ of the prescribers. The tendency of GPs and geriatricians to hand out prescriptions increased with the age of the patient, while the amount of prescriptions from psychiatrists, other specialists, and physicians with no specialist education decreased with age.

Among the dispensed substances, the most commonly prescribed were two benzodiazepine derivatives and one 
Table 2 Characteristics of the study population: number of persons in the older population and number of persons ( $n$ ) receiving dispensed drugs for mental disorders (MD) (ICD-10: F20-F42), mean age with standard deviation (SD), percentage men and women in the study population, and total number of dispensed drugs for mental disorders

\begin{tabular}{lccc}
\hline & $\mathbf{2 0 0 6}$ & $\mathbf{2 0 0 7}$ & $\mathbf{2 0 0 8}$ \\
\hline Older population, total $(n)$ & 1581437 & 1608413 & 1645081 \\
\hline Persons receiving drugs for MD $(n)$ & 104441 & 106665 & $77.8(7.8)$ \\
\hline Mean age (years) (SD) & $77.8(7.8)$ & $35 / 65$ & $77.7(7.9)$ \\
\hline Men/Women (\%) & $35 / 65$ & 671071 & $36 / 64$ \\
\hline Total number of dispensed drugs for MD & 639841 & 702167 \\
\hline
\end{tabular}

non-selective monoamine reuptake inhibitor (see Table 4). During 2006 to 2008, an average of $39 \%$ of the study population was prescribed the anxiolytic oxazepam, while approximately $18 \%$ was prescribed diazepam. The antidepressant amitriptyline was prescribed to $11 \%$ of the study population yearly, from 2006 to 2008. GPs represented the category of physicians that most commonly prescribed these top three ATC codes. While men and women both received equal amounts of prescriptions from geriatricians and psychiatrists, men received prescriptions from other specialists and physicians with no specialist education to a higher extent than women.

Each year approximately $15 \%$ of the older population received two or more substances for mental disorders on one or recurrent occasions during the years 2006, 2007 and 2008 (see Table 5). The prescription of one chemical

Table 3 Frequency of ATC codes prescribed to the study population

\begin{tabular}{|c|c|c|c|c|c|c|c|c|c|c|c|}
\hline \multirow[t]{2}{*}{ ATC } & \multirow[t]{2}{*}{ Chem. Sub. } & \multirow[t]{2}{*}{ ICD } & \multicolumn{3}{|c|}{2006} & \multicolumn{3}{|c|}{2007} & \multicolumn{3}{|c|}{2008} \\
\hline & & & $n$ & $\%$ & $95 \% \mathrm{Cl}$ & $n$ & $\%$ & $95 \% \mathrm{Cl}$ & $n$ & $\%$ & $95 \% \mathrm{Cl}$ \\
\hline N03AE01 & Clonazepam & 42 & 1015 & 0.97 & $0.91-1.03$ & 1082 & 1.01 & $0.95-1.07$ & 1097 & 1.01 & $0.95-1.07$ \\
\hline N03AF01 & Carbamazepin & 31 & 7917 & 7.58 & $7.42-7.74$ & 7877 & 7.38 & $7.23-7.54$ & 7814 & 7.21 & $7.06-7.37$ \\
\hline N03AG01 & Valproic acid & 31 & 2220 & 2.13 & $2.04-2.21$ & 2308 & 2.16 & $2.08-2.25$ & 2377 & 2.19 & $2.11-2.28$ \\
\hline N03AX09 & Lamotrigine & 31 & 1259 & 1.21 & $1.14-1.27$ & 1436 & 1.35 & $1.28-1.42$ & 1691 & 1.56 & $1.49-1.64$ \\
\hline N03AX16 & Pregabalin & 41 & 2641 & 2.53 & $2.43-2.62$ & 3982 & 3.73 & $3.62-2.85$ & 5231 & 4.83 & $4.70-4.96$ \\
\hline N04BC05 & Pramipexole & $30-39$ & 6188 & 5.92 & $5.78-6.07$ & 7807 & 7.32 & 7.16-7.48 & 9093 & 8.40 & $8.23-8.56$ \\
\hline N05BA01 & Diazepam & $20-39,41$ & 20075 & 19.22 & 18.98-19.46 & 19315 & 18.11 & $17.88-18.34$ & 18477 & 17.06 & $16.84-17.28$ \\
\hline N05BA04 & Oxazepam & $20-39,41$ & 41521 & 39.76 & $39.46-40.05$ & 41725 & 39.12 & $38.82-39.41$ & 41226 & 38.06 & $37.78-38.35$ \\
\hline N05BA06 & Lorazepam & $20-39,41$ & 1175 & 1.13 & $1.06-1.19$ & 1119 & 1.05 & $0.99-1.11$ & 1093 & 1.01 & $0.95-1.07$ \\
\hline N05BA12 & Alprazolam & $20-39,41$ & 3992 & 3.82 & $3.71-3.94$ & 3910 & 3.67 & $3.55-3.78$ & 3819 & 3.53 & $3.42-3.64$ \\
\hline N05BE01 & Buspirone & $30-39,41$ & 473 & 0.45 & $0.41-0.49$ & 422 & 0.40 & $0.36-0.43$ & 401 & 0.37 & $0.33-0.41$ \\
\hline N06AA04 & Clomipramine & $20-29,41-42$ & 2841 & 2.72 & $2.62-2.82$ & 2827 & 2.65 & $2.55-2.75$ & 2739 & 2.53 & $2.44-2.62$ \\
\hline N06AA06 & Trimipramine & $20-39$ & 342 & 0.33 & $0.29-0.36$ & 196 & 0.18 & $0.16-0.21$ & 48 & 0.04 & $0.03-0.06$ \\
\hline N06AA09 & Amitriptyline & $20-39$ & 11914 & 11.41 & $11.21-11.60$ & 11907 & 11.16 & $10.97-11.35$ & 12275 & 11.33 & $11.14-11.52$ \\
\hline N06AA10 & Nortriptyline & 20-39 & 381 & 0.36 & $0.33-0.40$ & 367 & 0.34 & $0.31-0.38$ & 307 & 0.28 & $0.25-0.32$ \\
\hline N06AA21 & Maprotiline & $20-39$ & 413 & 0.40 & $0.36-0.43$ & 342 & 0.32 & $0.29-0.35$ & 322 & 0.30 & $0.26-0.33$ \\
\hline N06AG02 & Moclobemide & $30-39$ & 186 & 0.18 & $0.15-0.20$ & 167 & 0.16 & $0.13-0.18$ & 152 & 0.14 & $0.12-0.16$ \\
\hline N06AX02 & Tryptophan & $30-39$ & 36 & 0.03 & $0.02-0.05$ & 37 & 0.03 & $0.02-0.05$ & 28 & 0.03 & $0.02-0.04$ \\
\hline N06AX03 & Mianserin & $30-39$ & 1575 & 1.51 & $1.43-1.58$ & 1527 & 1.43 & $1.36-1.50$ & 1523 & 1.41 & $1.34-1.48$ \\
\hline N06AX11 & Mirtazapine & $30-39$ & 9296 & 8.90 & $8.73-9.07$ & 10581 & 9.92 & $9.74-10.10$ & 11500 & 10.62 & $10.43-10.80$ \\
\hline N06AX12 & Bupropion & $30-39$ & 1552 & 1.49 & $1.31-1.56$ & 1264 & 1.19 & $1.12-1.25$ & 838 & 0.77 & $0.72-0.83$ \\
\hline N06AX16 & Venlafaxine & $30-39$ & 3792 & 3.63 & $3.52-3.74$ & 3848 & 3.61 & $3.50-3.72$ & 4126 & 3.81 & $3.70-3.92$ \\
\hline N06AX18 & Reboxetin & $30-39,41$ & 91 & 0.09 & $0.07-0.11$ & 74 & 0.07 & $0.05-0.09$ & 91 & 0.08 & $0.07-0.10$ \\
\hline N06AX21 & Duloxetine & $30-39$ & 1480 & 1.42 & $1.35-1.49$ & 1602 & 1.50 & $1.43-1.57$ & 2036 & 1.88 & $1.80-1.96$ \\
\hline N06BA07 & Modafinil & $30-39$ & 95 & 0.09 & $0.07-0.11$ & 125 & 0.12 & $0.10-0.14$ & 136 & 0.13 & $0.10-0.15$ \\
\hline
\end{tabular}

ATC codes (ATC), the corresponding chemical substances (Chem. Sub.) and ICD-10 codes F20-42 (ICD) (Chapter V Mental and behavioral disorders) to which the ATC codes can be prescribed, number of older persons $(n)$ prescribed each of ATC-codes level 5 and percentage (\%) of the older population being prescribed drugs for mental disorders, with $95 \% \mathrm{Cl}$, during 2006, 2007 and 2008 


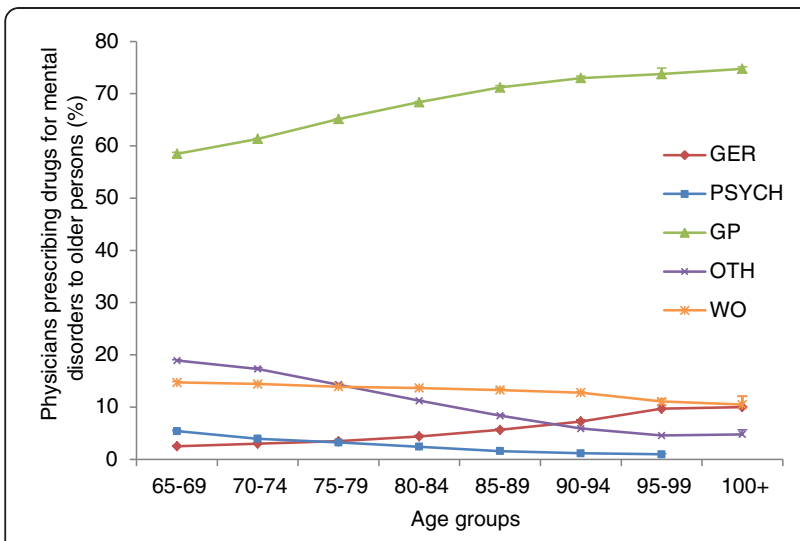

Figure 1 Percentage of physicians with specialist education in geriatrics (GER), psychiatry (PSYCH), general practitioners (GP), other specialists (OTH) or physicians without specialist education (WO) prescribing drugs for mental disorders (Y-axis) to older persons, in 5-year age brackets (X-axis). Data are presented as average values for the 3-year period (2006 to 2008) with SEM

substance tended to decrease, while there was a minor increase in the prescription of two and three chemical substances during the three years.

GPs prescribed drugs for mental disorders to both women and men to a high extent during all three years (see Figure 2). In 2006 the prescriptions written by geriatricians to women increased with increasing number of substances, while their prescribing to men was consistently low. The prescriptions written by psychiatrists to both men and women increased with increasing number of substances.

In 2007, both men and women were prescribed drugs from geriatricians and from physicians with no specialist education to a low extent. The prescriptions written by psychiatrists to women increased with increasing number of substances, while their prescribing to men decreased with more than five substances. In the year 2008, prescriptions by psychiatrists increased with increasing number of substances for both men and women.

\section{Discussion}

To our knowledge no other studies have evaluated the prescription of drugs for older persons with mental disorders other than dementia disorders, with a particular focus on the medical specialty of the prescribing physician. This study shows that GPs represented the main prescribers, whereas geriatricians and psychiatrists rarely prescribed drugs to older persons.

The study includes all older persons $(\geq 65)$ in Sweden who received drugs dispensed at national pharmacies and thus includes the vast majority of the older population. The prevalence of prescriptions for drugs for mental disorders corresponds to approximately $7 \%$ of the older population in Sweden [4]. In fact, each year, more than half a million such prescriptions are dispensed to the older population, and the most commonly prescribed drugs are anxiolytics (benzodiazepines: oxazepam and diazepam) and tricyclic antidepressants (amitriptyline). Although previous studies on potentially inappropriate drugs for older persons suggested that benzodiazepines and tricyclic antidepressants are associated with a high risk of adverse effects and should be replaced with safer alternative drugs or therapies [30,31], the present study indicates that the use of benzodiazepines and tricyclic antidepressants was frequent. Approximately $60 \%$ of the older population was prescribed benzodiazepines, and only a minor decrease was observed over the course of the study. Furthermore, antidepressants such as mirtazapine are shown to involve high risk for adverse effects, including stroke or attempted suicide [32], and despite its association with adverse effects in older persons, prescriptions for mirtazapine tended to increase over the years. These findings highlight the clinical relevance of thoroughly and regularly evaluating the continuous treatment of older persons.

Whereas approximately $85 \%$ of the older population received only one chemical substance intended for treating mental disorders, approximately $15 \%$ received two or more substances. Although this finding per se does not indicate polypharmacy or risk for adverse drug reactions, previous studies of the use of multiple drugs in older persons suggested that it may result in inferior self-rated health [33] and increased depressive symptoms [34].

The importance of expertise in geriatrics, gerontology and psychiatry when treating older persons in general and those with mental disorders in particular has been debated [35-37]. Physicians without specialist education prescribed all types of psychotropics, across all age groups. As licensed physicians without specialist education in Sweden have undergone at most two weeks of training and education in geriatrics [14], their prescribing behavior may be detrimental to the quality and adequacy of the treatment provided to older persons with mental disorders. The present study does, however, conclude that the majority of prescriptions for drugs for mental disorders were given by GPs, perhaps not surprising as GPs represent the majority of physicians in Sweden. GPs are recognized as an important part of psychiatric care [38]. In the present study, the tendency of GPs to prescribe drugs for mental disorders increased with the age of the patient. This corresponds to a previous study showing that although GPs are aware of the advantages of reducing the prescription of psychotropic drugs, they struggle to convince their older patients of the benefits of this [39].

A previous study has shown that licensed physicians, other than psychiatrists, inaccurately diagnose mental 
Table 4 The three most commonly prescribed drugs (classification, ATC-code level $\mathbf{5}$ and chemical substance) for mental disorders (ICD-10) from 2006 to 2008: number (n) of and percentage (\%), with $95 \% \mathrm{Cl}$, of older persons (men and women) prescribed drugs for mental disorders by specialists in geriatrics (GER), psychiatry (PSYCH), general practitioners (GP), other specialists (OTH) or by physicians without specialist education (WO)

\begin{tabular}{|c|c|c|c|c|c|c|c|c|c|c|c|c|}
\hline \multirow[t]{2}{*}{ Classification ATC Chem. Sub. } & \multirow[t]{2}{*}{ ICD-10 } & \multirow[t]{2}{*}{ Specialists } & \multirow[t]{2}{*}{ Patients' sex } & \multicolumn{3}{|c|}{2006} & \multicolumn{3}{|c|}{2007} & \multicolumn{3}{|c|}{2008} \\
\hline & & & & $n$ & $\%$ & $95 \% \mathrm{Cl}$ & $n$ & $\%$ & $95 \% \mathrm{Cl}$ & $n$ & $\%$ & $95 \% \mathrm{Cl}$ \\
\hline \multirow{2}{*}{$\begin{array}{l}\text { Benzodiazepine } \\
\text { derivative }\end{array}$} & F20-39, 41 & GER & Men & 470 & 4.0 & $3.6-4.3$ & 492 & 4.1 & $3.7-4.4$ & 551 & 4.6 & $4.2-4.9$ \\
\hline & & & Women & 1218 & 4.1 & $3.9-4.3$ & 1302 & 4.4 & $4.2-4.6$ & 1378 & 4.7 & $4.5-5.0$ \\
\hline N05BA04 & & PSYCH & Men & 394 & 3.3 & $3.0-3.7$ & 405 & 3.4 & $3.0-3.7$ & 413 & 3.4 & $3.1-3.8$ \\
\hline \multirow[t]{7}{*}{ Oxazepam } & & & Women & 815 & 2.7 & $2.6-2.9$ & 785 & 2.6 & $2.5-2.8$ & 793 & 2.7 & $2.5-2.9$ \\
\hline & & GP & Men & 8042 & 68.3 & $67.4-69.1$ & 8285 & 68.6 & $67.7-69.4$ & 8148 & 67.7 & $66.8-68.5$ \\
\hline & & & Women & 22132 & 74.4 & 73.9-74.9 & 22099 & 74.6 & $74.1-75.0$ & 21655 & 74.2 & $73.7-74.7$ \\
\hline & & $\mathrm{OTH}$ & Men & 1613 & 13.7 & $13.1-14.3$ & 1636 & 13.5 & $12.9-14.1$ & 1677 & 13.9 & $13.3-14.5$ \\
\hline & & & Women & 2929 & 9.8 & $9.5-10.2$ & 2905 & 9.8 & $9.5-10.1$ & 2816 & 9.6 & $9.3-10.0$ \\
\hline & & WO & Men & 1591 & 13.5 & $12.9-14.1$ & 1621 & 13.4 & $12.8-14.0$ & 1618 & 13.4 & $12.8-14.0$ \\
\hline & & & Women & 3462 & 11.6 & $11.3-12.0$ & 3462 & 11.7 & $11.3-12.0$ & 3419 & 11.7 & $11.3-12.1$ \\
\hline \multirow{2}{*}{$\begin{array}{l}\text { Benzodiazepine } \\
\text { derivative }\end{array}$} & F20-39, 41 & GER & Men & 262 & 3.5 & $3.1-3.9$ & 233 & 3.2 & $2.8-3.6$ & 247 & 3.6 & $3.2-4.0$ \\
\hline & & & Women & 477 & 3.8 & $3.4-4.1$ & 485 & 4.0 & $3.7-4.4$ & 481 & 4.1 & $3.8-4.5$ \\
\hline N05BA01 & & PSYCH & Men & 290 & 3.9 & $3.5-4.3$ & 295 & 4.0 & $3.6-4.5$ & 280 & 4.1 & $3.6-4.6$ \\
\hline \multirow[t]{7}{*}{ Diazepam } & & & Women & 415 & 3.3 & $3.0-3.6$ & 411 & 3.4 & $3.1-3.7$ & 422 & 3.6 & $3.3-4.0$ \\
\hline & & GP & Men & 4820 & 64.6 & $63.6-65.7$ & 4799 & 65.8 & $64.7-66.9$ & 4501 & 65.7 & $64.6-66.8$ \\
\hline & & & Women & 9024 & 71.5 & $70.7-72.3$ & 8577 & 71.4 & $70.6-72.2$ & 8324 & 71.6 & $70.8-72.4$ \\
\hline & & $\mathrm{OTH}$ & Men & 1374 & 18.4 & $17.5-19.3$ & 1263 & 17.3 & $16.4-18.2$ & 1145 & 16.7 & $15.8-17.6$ \\
\hline & & & Women & 1727 & 13.7 & $13.1-14.3$ & 1606 & 13.4 & $12.8-14.0$ & 1510 & 13.0 & $12.4-13.6$ \\
\hline & & WO & Men & 902 & 12.1 & $11.4-12.8$ & 886 & 12.1 & $11.4-12.9$ & 854 & 12.5 & $11.7-13.2$ \\
\hline & & & Women & 1308 & 10.4 & 9.8-10.9 & 1280 & 10.7 & $10.1-11.2$ & 1239 & 10.7 & $10.2-11.2$ \\
\hline \multirow{3}{*}{$\begin{array}{l}\text { Non-selective monoamine } \\
\text { reuptake inhibitor }\end{array}$} & F20-39 & GER & Men & 125 & 3.6 & $3.0-4.3$ & 107 & 3.2 & $2.6-3.7$ & 106 & 2.9 & $2.4-3.5$ \\
\hline & & & Women & 269 & 3.2 & $2.8-3.5$ & 280 & 3.3 & $2.9-3.7$ & 276 & 3.2 & $2.8-3.6$ \\
\hline & & PSYCH & Men & 101 & 2.9 & $2.4-3.5$ & 95 & 2.8 & $2.2-3.4$ & 97 & 2.7 & $2.2-3.2$ \\
\hline N06AA09 & & & Women & 269 & 3.2 & $2.8-3.5$ & 251 & 2.9 & $2.6-3.3$ & 254 & 2.9 & $2.6-3.3$ \\
\hline \multirow[t]{6}{*}{ Amitriptyline } & & GP & Men & 2133 & 62.1 & $60.5-63.8$ & 2172 & 64.0 & $62.4-65.6$ & 2276 & 63.1 & $61.5-64.7$ \\
\hline & & & Women & 5868 & 69.2 & $68.2-70.2$ & 5957 & 70.0 & $69.0-70.9$ & 6082 & 70.2 & $69.2-71.1$ \\
\hline & & $\mathrm{OTH}$ & Men & 585 & 17.0 & $15.8-18.3$ & 553 & 16.3 & $15.1-17.5$ & 624 & 17.3 & $16.1-18.5$ \\
\hline & & & Women & 1038 & 12.2 & $11.5-12.9$ & 1100 & 12.9 & $12.2-13.6$ & 1133 & 13.1 & $12.4-13.8$ \\
\hline & & WO & Men & 568 & 16.5 & $15.2-17.8$ & 531 & 15.7 & 14.4-16.9 & 569 & 15.8 & $14.6-17.0$ \\
\hline & & & Women & 1254 & 14.8 & $14.0-15.5$ & 1143 & 13.4 & $12.7-14.1$ & 1145 & 13.2 & $12.5-13.9$ \\
\hline
\end{tabular}

disorders in older persons, and consequently prescribe inappropriate drugs [40]. Improved knowledge of geriatric psychiatry, including alternative treatments for older persons with mental disorders, would likely lead to the decrease in inappropriate prescription of drugs. However, although previous research has provided strong evidence on how to improve the care of older persons with mental disorders, translation into practice is rare $[41,42]$. Older persons with mental disorders are consequently subjected to lack of evidence-based care. To facilitate the translation of research into practice and to meet the need for specialists in geriatric psychiatry, it is essential to launch new extended educational programs for geriatricians and psychiatrists, as well as geriatric psychiatrists
[43]. At present, only 60\% trained geriatricians in Sweden continue to work with older persons throughout their careers [14]; low numbers of geriatricians indicates that most older persons are treated by other specialists and could explain the relatively low percentage of drugs prescribed by geriatricians. The proportion of prescriptions from geriatricians is overall low, but does increase up to $10 \%$ with increasing age of the patients; this may reflect the tendency of older persons to be treated by geriatricians as they approach 100 years of age. The proportion of prescriptions written by psychiatrists is also remarkably low: only $5 \%$ of the older persons aged 65 to 69 received prescriptions from psychiatrists and this percentage decreased further with increasing age. 
Table 5 Number $(n)$ and percentage (\%) of the older population age $\geq 65$ in Sweden receiving prescriptions for one to eight chemical substances for mental disorders, during the years 2006, 2007 and 2008

\begin{tabular}{|c|c|c|c|c|c|c|c|c|c|c|c|c|c|c|c|c|c|c|}
\hline \multirow[t]{3}{*}{ ATC } & \multicolumn{6}{|c|}{2006} & \multicolumn{6}{|c|}{2007} & \multicolumn{6}{|c|}{2008} \\
\hline & \multicolumn{2}{|c|}{ Total } & \multicolumn{2}{|c|}{ Men } & \multicolumn{2}{|c|}{ Women } & \multicolumn{2}{|c|}{ Total } & \multicolumn{2}{|c|}{ Men } & \multicolumn{2}{|c|}{ Women } & \multicolumn{2}{|c|}{ Total } & \multicolumn{2}{|c|}{ Men } & \multicolumn{2}{|c|}{ Women } \\
\hline & $n$ & (\%) & $n$ & (\%) & $n$ & (\%) & $n$ & (\%) & $n$ & (\%) & $n$ & (\%) & $n$ & (\%) & $n$ & (\%) & $n$ & (\%) \\
\hline 1 & 89046 & (85.3) & 31380 & (86.5) & 57666 & (84.6) & 90369 & (84.7) & 32314 & (85.8) & 58055 & $(84.1)$ & 91368 & (84.4) & 32960 & (85.6) & 58407 & $(83.7)$ \\
\hline 2 & 13191 & (12.6) & 4175 & (11.5) & 9015 & (13.2) & 13871 & (13.0) & 4550 & $(12.1)$ & 9320 & (13.5) & 14308 & (13.2) & 4695 & $(12.2)$ & 9613 & (13.8) \\
\hline 3 & 1848 & $(1.77)$ & 599 & $(1.65)$ & 1249 & $(1.83)$ & 2037 & $(1.91)$ & 662 & (1.76) & 1375 & (1.99) & 2160 & $(1.99)$ & 688 & (1.79) & 1472 & $(2.11)$ \\
\hline 4 & 295 & $(0.28)$ & 81 & $(0.22)$ & 214 & $(0.31)$ & 328 & $(0.31)$ & 102 & $(0.27)$ & 226 & $(0.33)$ & 387 & $(0.36)$ & 136 & $(0.35)$ & 251 & $(0.36)$ \\
\hline 5 & 51 & $(0.05)$ & 19 & $(0.05)$ & 32 & $(0.05)$ & 49 & $(0.05)$ & 11 & $(0.03)$ & 38 & $(0.06)$ & 72 & $(0.07)$ & 24 & $(0.06)$ & 48 & $(0.07)$ \\
\hline 6 & 7 & $(0.01)$ & 3 & $(0.01)$ & 4 & $(0.01)$ & 9 & $(0.01)$ & 4 & $(0.01)$ & 5 & $(0.01)$ & 9 & $(0.01)$ & 6 & $(0.02)$ & 3 & $(0.00)$ \\
\hline 7 & 2 & $(0.00)$ & 1 & $(0.00)$ & 1 & $(0.00)$ & 2 & $(0.00)$ & & & 2 & $(0.00)$ & 2 & $(0.00)$ & 2 & $(0.01)$ & & \\
\hline 8 & 1 & $(0.00)$ & 1 & $(0.00)$ & & & & & & & & & & & & & & \\
\hline Total & 104441 & $(100)$ & 36259 & (100) & 68181 & $(100)$ & 106665 & $(100)$ & 37643 & $(100)$ & 69021 & $(100)$ & 108306 & $(100)$ & 38511 & (100) & 69794 & $(100)$ \\
\hline
\end{tabular}

The present study shows that women who are dispensed several substances tend to receive their prescriptions from geriatricians and psychiatrists to a higher extent than men. It has been demonstrated that women in old age are more likely to be affected by mental disorders [44] and receive mental health care than men [45]; this may have increased the awareness of mental health issues among older women and led to more frequent referrals of women with mental disorders to specialists such as geriatricians and psychiatrists. This supports the necessity of continuing the discussion on gender differences in old age psychiatry and it becomes evident that new and improved approaches in the care of older persons are of utmost importance for providing the older population with adequate care and treatment.

Given the complexity and challenges entailed in providing care for older persons, an increase in the number of geriatric specialists with improved competence in psychiatry or the involvement of teams of different specialists may positively contribute to improving the quality of care. Communication between GPs and other specialists is vital for improving the care and treatment of older persons in general [46] as well as older persons with mental disorders $[47,48]$. In order to assist healthcare personnel in providing the highest quality care to older persons with mental disorders, it is necessary to provide appropriate and effective drug treatment.

\section{Strengths and limitations}

The SPDR includes all prescriptions dispensed at national pharmacies and consequently includes the vast majority of the population in Sweden. The study population therefore consisted of approximately 200000 older persons, which must be considered as a strength of this study. Nonetheless, this study had some limitations. Drugs that could be used for dementia disorders have been excluded which may have led to some types of selection bias. Due to the lack of diagnoses in the register, drug use was used as a proxy for diagnoses. Consequently, it is likely that some of the drugs that were excluded due to plausible use for dementia disorders may have been prescribed for an actual diagnosis and treatment for a mental disorder and should have been included in the study (diagnosis bias). The lack of diagnoses is a crucial limitation that may have decreased the validity of the results. To counteract this bias as far as possible, the treatment guidelines and recommendations set for each year of the study were thoroughly scrutinized and each disorder and ATC code was evaluated with the help of practicing psychiatrists in order to minimize inaccuracy. Drugs recommended as firsthand options for treating dementia disorders or symptoms during the years of the study were excluded to facilitate studying mental disorders besides dementia disorders. Consequently, this brought an unfortunate exclusion of SSRIs and antipsychotics. In addition, with the register lacking diagnoses the included drugs may have been prescribed on indications other than mental disorders; tricyclic antidepressants may be prescribed for e.g. neuropathic pain rather than depression. However, as this study aimed to present what medical specialties the prescribers hold rather than the prevalence of certain disorders, each disorder and connected drugs, including all antidepressants and antipsychotics, will be further analyzed in future studies.

With the character of the national register generalizations to older populations outside Sweden must be made with consideration. One important limitation is that the register does not include diagnoses. As a result of this limitation the interpretation of the results with respect to diagnoses and disorders may affect the outcome as the differences in prescribing rates by different specialists could be altered if diagnoses were to be included. However, the register does deliver reliable information about the 


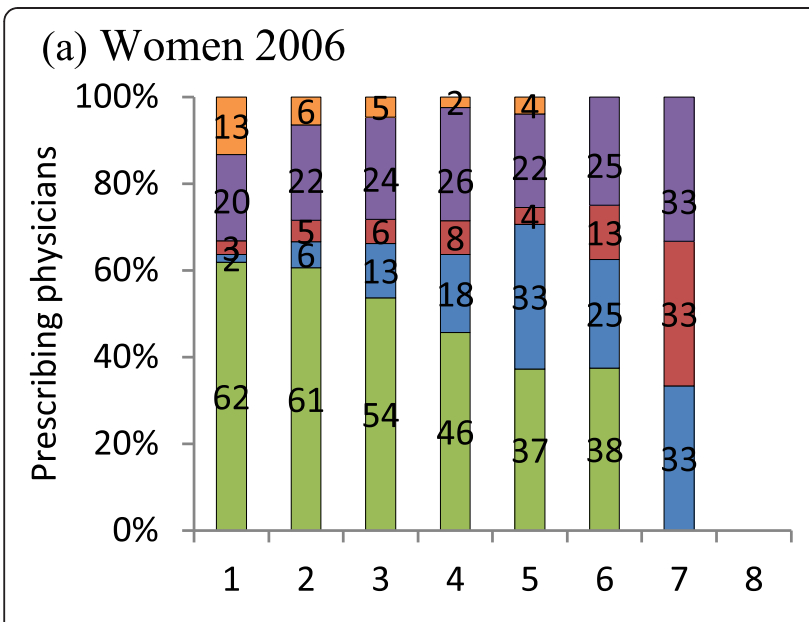

No. of dispensed ATC codes per person

(c) Women 2007

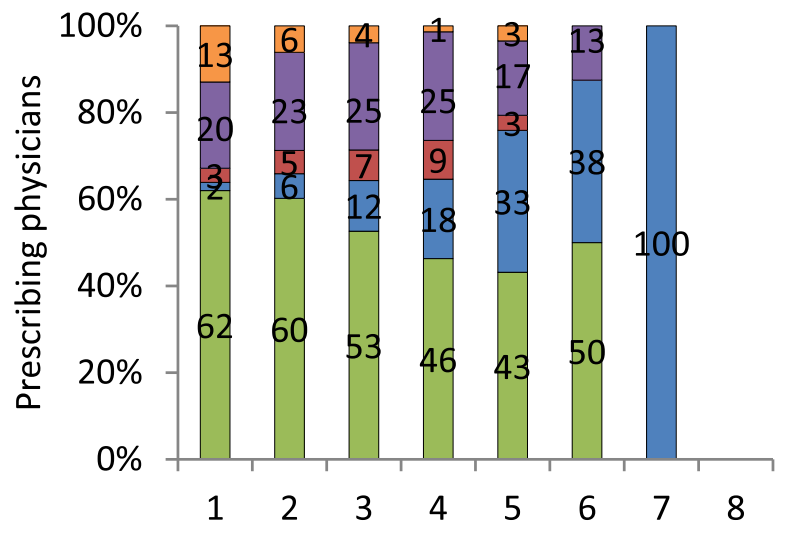

No. of dispensed ATC codes per person

(e) Women 2008

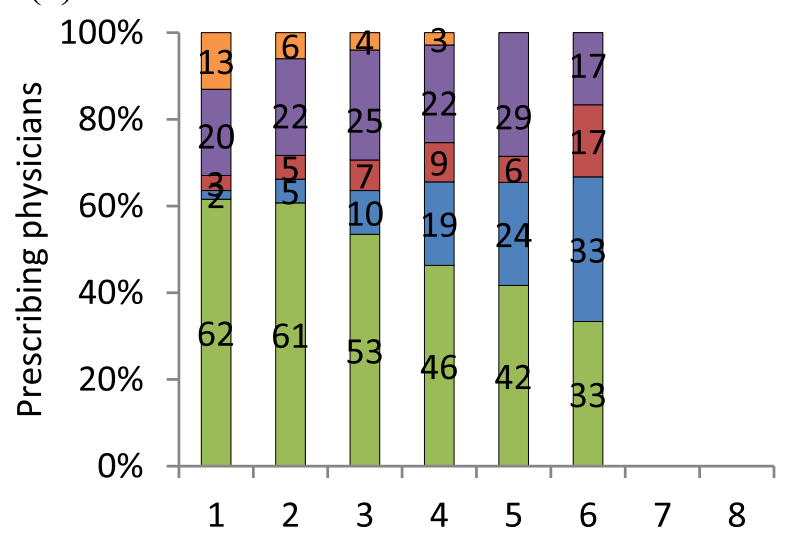

No. of dispensed ATC codes per person

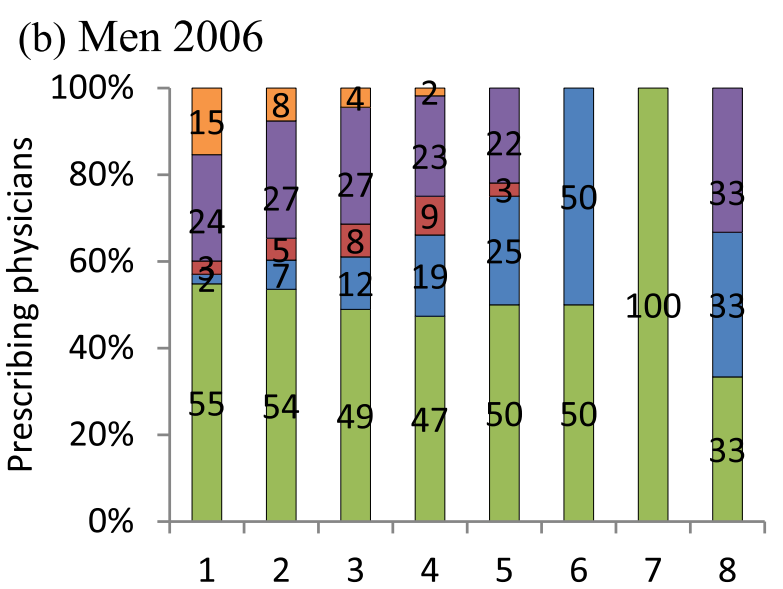

No. of dispensed ATC codes per person

(d) Men 2007

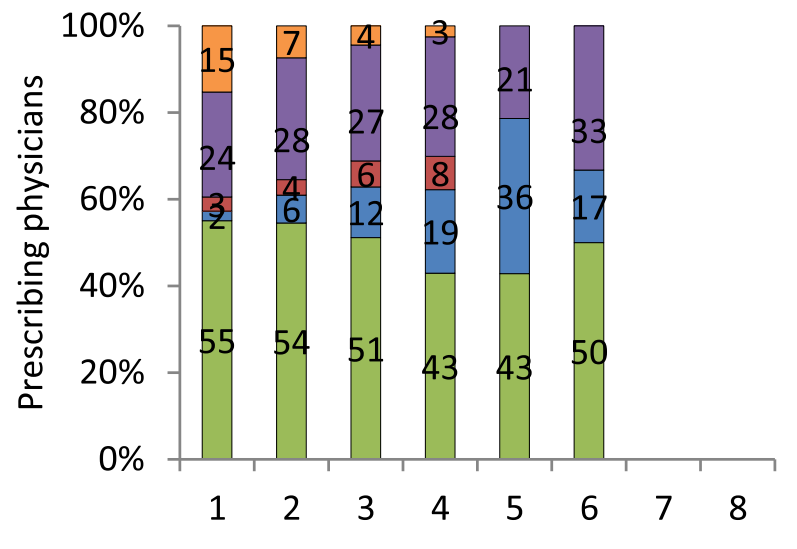

No. of dispensed ATC codes per person

(f) Men 2008

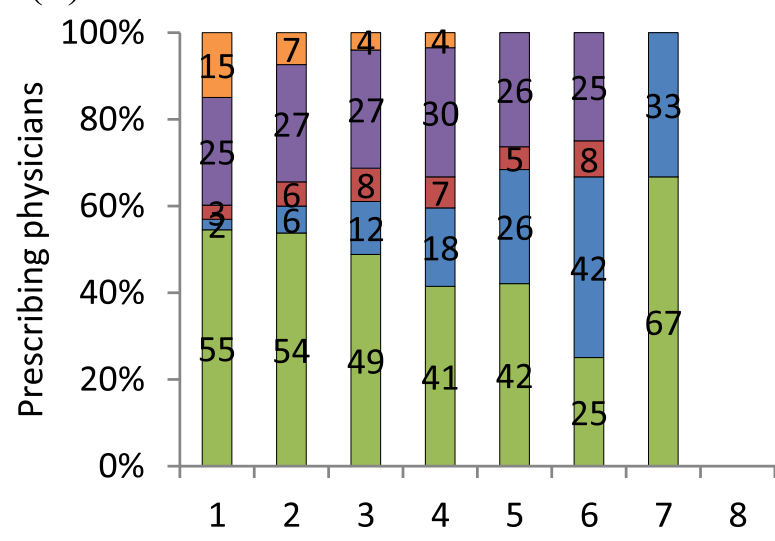

No. of dispensed ATC codes per person

\section{IGP $\square$ PSYCH $\square$ GER $\square$ OTH $\square$ WO}

Figure 2 Percentage of physicians with specialist education in geriatrics (GER), psychiatry (PSYCH), general practitioners (GP), other specialists (OTH) or physicians without specialist education (WO) prescribing one or more ATC codes, level 5 (chemical substance) for mental disorders to women (a, c, e) and men (b, d, f) during the years 2006, 2007 and 2008. 
competences of the prescribing physicians. Questions regarding alternative therapies and non-pharmacological treatment were not within the scope of this study. However, it would be of interest to study the frequency of prescriptions for non-pharmacological treatments by the various specialist categories. In addition, whether or not the prescribing rates by different specialists differ depending on the characteristics of the drug remain unclear and consequently future studies will include studying the prescribing rates when including e.g. SSRIs in the analyses. Possibly the prescribing differences between specialists and physicians without specialist education depend on specialists recurring more frequently to other classes of drugs different from those used by physicians without specialist education. Hence future studies may answer questions as to whether or not psychiatrists and/or geriatricians prescribe alternative treatments to a greater extent than other specialists or, alternatively, if the degree of patient contact with these specialists is overall low. In future studies we will also examine subsamples of the population and their prescriptions will be further scrutinized with respect to daily doses and comparisons to the general recommendations in order to further elucidate the subject.

\section{Conclusions}

The majority of prescriptions of drugs for mental disorders were made by GPs and not by specialists on disorders affecting the older population (geriatricians) or specialists on mental disorders (psychiatrists). The most commonly prescribed drugs were the benzodiazepines oxazepam and diazepam, as well as the tricyclic antidepressant amitriptyline, despite the fact that clinical guidelines do not recommend these medications for regular use in older persons. Approximately $15 \%$ of the older population receiving drugs for mental disorders received several substances. The results highlight the importance of regularly evaluating pharmaceutical prescriptions to older persons and raise questions about whether the involvement of more geriatric or psychiatric specialists would improve overall care.

\section{Competing interests}

The authors declare that they have no competing interests.

\section{Authors' contributions}

GM participated in the study design, data collection, data analysis, interpretation of the results, and drafting of the manuscript. IF and LWG participated in the study design, interpretation of the results and drafting of the manuscript. CL participated in the design of the study, data collection, data analysis, interpretation of the results and drafting of the manuscript. All authors read and approved the final manuscript.

\section{Acknowledgements}

We thank Dr. Rachel Thomas for linguistic revision. Financial support for this study was granted by the Karolinska Institutet Health Care Sciences Postgraduate School and the School of Health, Care and Social Welfare at Mälardalen University.

\section{Author details}

${ }^{1}$ Department of Neurobiology, Care Sciences and Society, Karolinska Institutet, Stockholm, Sweden. ${ }^{2}$ School of Health, Care and Social Welfare, Mälardalen University, Västerås, Sweden. ${ }^{3}$ Department of Health Care Sciences, Ersta Sköndal University College, Stockholm, Sweden. ${ }^{4}$ Faculty of Health and Society, Narvik University College, Narvik, Norway. ${ }^{5}$ Department of Clinical Neuroscience, Karolinska Institutet, Stockholm, Sweden.

Received: 27 January 2012 Accepted: 4 November 2012

Published: 13 November 2012

\section{References}

1. Bunting BP, Murphy SD, O'Neill SM, Ferry FR: Lifetime prevalence of mental health disorders and delay in treatment following initial onset: evidence from the Northern Ireland Study of Health and Stress. Psychol Med 2011, 42(8):1-13.

2. Jongenelis K, Pot AM, Eisses AM, Beekman AT, Kluiter H, Ribbe MW: Prevalence and risk indicators of depression in elderly nursing home patients: the AGED study. J Affect Disord 2004, 83(2-3):135-142

3. Olivera J, Benabarre S, Lorente T, Rodríguez M, Pelegrín C, Calvo JM, Leris JM, Idáñez D, Arnal S: Prevalence of psychiatric symptoms and mental disorders detected in primary care in an elderly Spanish population. The PSICOTARD Study: preliminary findings. Int J Geriatr Psychiatry 2008, 23(9):915-921.

4. Martinsson G, Wiklund-Gustin L, Fagerberg I, Lindholm C: Mental disorders affect older persons in Sweden-a register-based study. Int J Geriatr Psychiatry 2011, 26(3):277-283.

5. Sigstrom R, Skoog I, Sacuiu S, Karlsson B, Klenfeldt IF, Waern M, Gustafson D, Ostling S: The prevalence of psychotic symptoms and paranoid ideation in non-demented population samples aged 70-82 years. Int J Geriatr Psychiatry 2009, 24(12):1413-1419.

6. National Board of Health and Welfare: Öppna jämförelser 2011-Vård och omsorg om äldre [The care of older persons 2011]. Stockholm with reference number 2011-12-5: National Board of Health and Welfare; 2011.

7. Alonso J, Angermeyer MC, Bernert S, Bruffaerts R, Brugha TS, Bryson H, de Girolamo G, de Graaf R, Demyttenaere K, Gasquet I, Haro JM, Katz SJ, Kessler RC, Kovess V, Lepine JP, Ormel J, Polidori G, Russo LJ, Vilagut G: Psychotropic drug utilization in Europe: results from the European Study of the Epidemiology of Mental Disorders (ESEMeD) project. Acta Psychiatr Scand 2004, 109(420):55-64.

8. Johnell K, Fastbom J, Rosen M, Leimanis A: Inappropriate drug use in the elderly: a nationwide register-based study. Ann Pharmacother 2007, 41(7):1243-1248.

9. Johnell K, Fastbom J: Multi-dose drug dispensing and inappropriate drug use: A nationwide register-based study of over 700,000 elderly. Scand J Prim Health Care 2008, 26(2):86-91.

10. Hosia-Randell HM, Muurinen SM, Pitkala KH: Exposure to potentially inappropriate drugs and drug-drug interactions in elderly nursing home residents in Helsinki, Finland: a cross-sectional study. Drugs Aging 2008, 25(8):683-692

11. Mjorndal T, Boman MD, Hagg S, Backstrom M, Wiholm BE, Wahlin A, Dahlqvist $R$ : Adverse drug reactions as a cause for admissions to a department of internal medicine. PDS 2002, 11(1):65-72.

12. Tai-Seale M, McGuire T, Colenda C, Rosen D, Cook MA: Two-minute mental health care for elderly patients: inside primary care visits. JAGS 2007, 55(12):1903-1911.

13. Bergman A, Olsson J, Carlsten A, Waern M, Fastbom J: Evaluation of the quality of drug therapy among elderly patients in nursing homes. Scand J Prim Health Care 2007, 25(1):9-14.

14. National Board of Health and Welfare: Ökad kompetens inom geriatrik och gerontologi [Increased competence within geriatrics and gerontology] (In Swedish). Stockholm 2011-3-34: National Board of Health and Welfare; 2011.

15. National Board of Health and Welfare: Statistik om hälso- och sjukvårdspersonal - Officiell statistik om antal legitimerade (2010) och arbetsmarknadsstatus (2009) [Statistics- Health and Medical Care - Statistics on Health Care Personnel - Official Statistics on the Number of Licensed Practitioners (2010) and their Labour Market Situation (2009)]. Stockholm 2011-11-13: National Board of Health and Welfare; 2011.

16. Rahmner PB, Gustafsson LL, Holmstrom I, Rosenqvist U, Tomson G: Whose job is it anyway? Swedish general practitioners' perception of their responsibility for the patient's drug list. Ann Fam Med 2010, 8(1):40-46. 
17. Stuck AE, Siu AL, Wieland GD, Adams J, Rubenstein LZ: Comprehensive geriatric assessment: a meta-analysis of controlled trials. Lancet 1993, 342(8878):1032-1036.

18. Saltvedt I, Mo ES, Fayers P, Kaasa S, Sletvold O: Reduced mortality in treating acutely sick, frail older patients in a geriatric evaluation and management unit. A prospective randomized trial. JAGS 2002, 50(5):792-798.

19. Ellis $G$, Whitehead MA, Robinson D, O'Neill D, Langhorne P: Comprehensive geriatric assessment for older adults admitted to hospital: meta-analysis of randomised controlled trials. BMJ 2011, 343:d6553. doi:10.1136/bmj.d6553.

20. Baztan JJ, Suarez-Garcia FM, Lopez-Arrieta J, Rodriguez-Manas L, RodriguezArtalejo F: Effectiveness of acute geriatric units on functional decline, living at home, and case fatality among older patients admitted to hospital for acute medical disorders: meta-analysis. BMJ 2009, 338:b50. doi:10.1136/bmj.b50.

21. Fried TR, Tinetti ME, lannone L: Primary care clinicians' experiences with treatment decision making for older persons with multiple conditions. Arch Intern Med 2011, 171(1):75-80.

22. Stuijt CC, Franssen EJ, Egberts AC, Hudson SA: Appropriateness of prescribing among elderly patients in a Dutch residential home: observational study of outcomes after a pharmacist-led medication review. Drugs Aging 2008, 25(11):947-954

23. Hori H, Richards M, Kawamoto Y, Kunugi H: Attitudes toward schizophrenia in the general population, psychiatric staff, physicians, and psychiatrists: a web-based survey in Japan. Psychiatry Res 2011, 186(2-3):183-189.

24. World Health Organization: The International Statistical Classification of Disease and Related Health Problems, Tenth Revision (ICD-10), Swedish version. World Health Organization; 2009. Retrieved in 2009 from http://www.who. int/classifications/icd/.

25. LIF: The Swedish Medicines Information portal, The Research-based Pharmaceutical Industry, LIF. Stockholm: LIF; 2009. http://www.FASS.se.

26. FASS: FASS (Farmacevtiska specialiteter i Sverige) 2006, (In Swedish) [Pharmaceutical specialities in Sweden]. Stockholm, Sweden: The Swedish Association of the Pharmaceutical Industry. LIF; 2006.

27. FASS: FASS (Farmacevtiska specialiteter i Sverige) 2007, (In Swedish) [Pharmaceutical specialities in Sweden]. Stockholm, Sweden: The Swedish Association of the Pharmaceutical Industry. LIF; 2007.

28. FASS: FASS (Farmacevtiska specialiteter i Sverige) 2008, (In Swedish) [Pharmaceutical specialities in Sweden]. Stockholm, Sweden: The Swedish Association of the Pharmaceutical Industry. LIF; 2008.

29. World Medical Association: WMA Declaration of Helsinki - Ethical Principles for Medical Research Involving Human Subjects. 2008. http://www.wma.net/en/ 30publications/10policies/b3/.

30. Laroche ML, Charmes JP, Merle L: Potentially inappropriate medications in the elderly: a French consensus panel list. Eur J Clin Pharmacol 2007, 63(8):725-731.

31. Madhusoodanan S, Bogunovic OJ: Safety of benzodiazepines in the geriatric population. Expert Opin Drug Saf 2004, 3(5):485-493.

32. Coupland CA, Dhiman P, Barton G, Morriss R, Arthur A, Sach T, Hippisley-Cox $\mathrm{J}$ : A study of the safety and harms of antidepressant drugs for older people: a cohort study using a large primary care database. Health Tech Ass 2011, 15(28):1-202. iii-iv.

33. Moen J, Antonov K, Larsson CA, Lindblad U, Nilsson JL, Rastam L, Ring L: Factors associated with multiple medication use in different age groups. Ann Pharmacother 2009, 43(12):1978-1985.

34. Puustinen J, Nurminen J, Kukola M, Vahlberg T, Laine K, Kivela SL: Associations between use of benzodiazepines or related drugs and health, physical abilities and cognitive function: a non-randomised clinical study in the elderly. Drugs Aging 2007, 24(12):1045-1059.

35. Arai $H$, Ouchi $Y$, Yokode $M$, Ito H, Uematsu H, Eto F, Oshima S, Ota K, Saito Y, Sasaki H, Tsubota K, Fukuyama H, Honda Y, Iguchi A, Toba K, Hosoi T, Kita $\mathrm{T}$ : Toward the realization of a better aged society: Messages from gerontology and geriatrics. Geriatr Gerontol Int 2012, 12(1):16-22.

36. Moak GS: Treatment of late-life mental disorders in primary care: we can do a better job. J Aging Social policy 2011, 23(3):274-285.

37. George J, Adamson J, Woodford H: Joint geriatric and psychiatric wards: a review of the literature. Age Ageing 2011, 40(5):543-548.

38. Fredheim T, Danbolt $\sqcup$, Haavet OR, Kjonsberg K, Lien L: Collaboration between general practitioners and mental health care professionals: a qualitative study. Int J Ment Health Sys 2011, 5(1):13. doi:10.1186/1752-4458-5-13.
39. Lasserre A, Younes N, Blanchon T, Cantegreil-Kallen I, Passerieux C, Thomas G, Chan-Chee C, Hanslik T: Psychotropic drug use among older people in general practice: discrepancies between opinion and practice. $\mathrm{Br} J \mathrm{Gen}$ Pract 2010, 60(573):e156-162.

40. Yamada K, Hosoda M, Nakashima S, Furuta K, Awata S: Psychiatric diagnosis in the elderly referred to a consultation-liaison psychiatry service in a general geriatric hospital in Japan. Geriatr Gerontol Int 2012, 12(2):304-309.

41. Ell K: Depression care for the elderly: reducing barriers to evidencebased practice. Home Health Care Serv Q 2006, 25(1-2):115-148.

42. Schuurmans J, van Balkom A: Late-life anxiety disorders: a review. Curr Psychiatry Rep 2011, 13(4):267-273.

43. Ribeiro O, Fernandes L, Firmino H, Simoes MR, Paul C: Geropsychology and psychogeriatrics in Portugal: research, education and clinical training. Int Psychoger 2010, 22(6):854-863.

44. Olafsdottir M, Marcusson J, Skoog I: Mental disorders among elderly people in primary care: the Linkoping study. Acta Psychiatr Scand 2001, 104(1):12-18.

45. Han B, Gfroerer JC, Colpe LJ, Barker PR, Colliver JD: Serious psychological distress and mental health service use among community-dwelling older U.S. adults. Psych Services 2011, 62(3):291-298.

46. Moen J, Norrgard S, Antonov K, Nilsson JL, Ring L: GPs' perceptions of multiple-medicine use in older patients. JECP 2010, 16(1):69-75.

47. Jones SM, Vahia IV, Cohen Cl, Hindi A, Nurhussein M: A pilot study to assess attitudes, behaviors, and inter-office communication by psychiatrists and primary care providers in the care of older adults with schizophrenia. Int J Geriatr Psych 2009, 24(3):254-260.

48. Anthony JS, Baik SY, Bowers BJ, Tidjani B, Jacobson CJ, Susman J: Conditions that influence a primary care clinician's decision to refer patients for depression care. Rehabil Nurs 2010, 35(3):113-122.

doi:10.1186/1471-244X-12-197

Cite this article as: Martinsson et al:: Specialist prescribing of psychotropic drugs to older persons in Sweden - a register-based study of 188024 older persons. BMC Psychiatry 2012 12:197.

\section{Submit your next manuscript to BioMed Central and take full advantage of:}

- Convenient online submission

- Thorough peer review

- No space constraints or color figure charges

- Immediate publication on acceptance

- Inclusion in PubMed, CAS, Scopus and Google Scholar

- Research which is freely available for redistribution 